\title{
Reduction of galectin-3 expression reduces pituitary tumor cell progression
}

\author{
C.X. Huang, J.N. Zhao, W.H. Zou, J.J. Li, P.C. Wang, C.H. Liu and Y.B. Wang \\ Department of Neurosurgery, Hainan Provincial People's Hospital, \\ Haikou, China \\ Corresponding author: C.X. Huang \\ E-mail: ChuixueHuang@126.com
}

Genet. Mol. Res. 13 (3): 6892-6898 (2014)

Received July 11, 2013

Accepted January 30, 2014

Published August 29, 2014

DOI http://dx.doi.org/10.4238/2014.August.29.11

\begin{abstract}
We investigated the role of galectin 3 in the development and progression of pituitary tumors. We used RNA interference to depress Gal-3 gene expression; MTT and flow cytometry were applied to detect changes in cell proliferation and apoptosis levels in pituitary tumor cells. Expression of apoptosisassociated genes, Bcl-2 and Baxk was analyzed by Western blot. Inhibition of Gal-3 gene expression by RNA interference decreased GH3 cell proliferation and increased cell apoptosis; the expression levels of Gal-3 protein significantly decreased, along with those of Bcl-2, although Bax levels did not change. We conclude that Gal3 has an important role in pituitary tumor cell proliferation and progression; and it may be useful as a target for the treatment of aggressive pituitary tumors.
\end{abstract}

Key words: Pituitary neoplasm; Galectin-3; Cell apoptosis 


\section{INTRODUCTION}

Galectins are a family of carbohydrate-binding proteins with a high affinity for $\beta$-galactoside. Although at least 13 different members of the family are involved with $\beta-1,3,(4)$-galactosylation (Lee et al., 2009), Gal-3, the only chimeric gene product, is one of the most frequently investigated members of the group. Gal-3 is involved in many biological processes, including cell growth and differentiation, cell adhesion, angiogenesis, tumor progression, apoptosis, and metastasis (Zhang et al., 2009; Sakaki et al., 2010; Jia et al., 2013; Wu et al., 2013).

Gal-3 is highly expressed in many human tumors and cell lines, including thyroid, colon, and breast (Arfaoui-Toumi et al., 2010; Manivannan et al., 2012; Yamaki et al., 2013). We examined Gal-3 expression in invasive and noninvasive pituitary tumors (Huang et al., 2008). In this paper, we conducted RNA interference experiments to investigate the effects of Gal-3 on pituitary tumor cells proliferation and cells apoptosis.

\section{MATERIAL AND METHODS}

\section{Cell culture}

The GH3 cell line was maintained in DMEM supplemented with $15 \%$ horse serum, $2.5 \%$ fetal bovine serum, $1 \%$ antibiotic-antimycotic $(100 \mathrm{U} / \mathrm{mL}$ penicillin $\mathrm{G}, 100 \mu \mathrm{g} / \mathrm{mL}$ streptomycin sulfate) in a humidified incubator at $37^{\circ} \mathrm{C}$ and $5 \% \mathrm{CO}_{2}$.

\section{RNA interference experiments}

RNA interference experiments were performed with cultured GH3 cells according to the manufacturer protocol (Dharmacon Research, Lafayette, CO, USA) (Liu and Rabinovich, 2005). siRNA duplexes targeting Gal-3 were prepared by annealing two pairs of 21-ribonucleotide oligonucleotides synthesized by Dharmacon Research. The coding strand was 5'-AGC GGA AAA UGG CAG ACA AAA-3' (GenBank Accession No. BC001120). GH3 cells were transfected with Trans IT-TKO transfection reagent on a 24 -well plate with $1 \times 10^{5}$ cells. Control dishes received a scrambled I duplex RNA, whereas the parental cell line was treated with Trans IT-TKO only. Sixteen hours after transfection, the $2 \%$ serum was replaced with complete medium, and cells were grown for another 3 days. The cells were then harvested and used for Western blotting, proliferation, and apoptosis assays.

\section{Transfection with antisense plasmid}

GH3 cells were transfected in a serum-free medium with either the $\mathrm{pCNC} 10$ vector or pCNC10Gal3AS (pCNC10 containing a human Gal-3 insert in the antisense orientation) 6, with the use of the GenePorter transfection reagent (Gene Therapy Systems, San Diego, CA, USA). Three days after transfection, $50 \mu \mathrm{g} / \mathrm{mL}$ Geneticin (Life Technologies, Inc.) was added and cells incubated for 1 week; the cells were then maintained in $2 \mu \mathrm{g} / \mathrm{mL}$ Geneticin for 1 week and $1 \mu \mathrm{g} / \mathrm{mL}$ Geneticin thereafter. 


\section{Cell proliferation}

After 4 days of treatment, $20 \mu \mathrm{L}$ MTT solution was added and cells incubated for $4 \mathrm{~h}$. The MTT solution and culture medium were removed, followed by washing three times with PBS. DMSO was added to dissolve formazan crystals. The plates were read within $30 \mathrm{~min}$ on a Bio-kinetics EL372C Microelisa reader, using a test wavelength of $570 \mathrm{~nm}$ and reference wavelength of $630 \mathrm{~nm}$.

\section{Cell apoptosis}

For analysis of apoptosis, an aliquot of GH-3 cells was harvested, placed on slides by cytocentrifugation, and fixed in $75 \%$ cold ethanol for one night. Apoptosis was analyzed by FCM.

\section{Western blotting}

Western blot analysis was performed as previously reported (Manivannan et al., 2012). The anti-Gal-3, anti-Bcl-2 and anti-Bax (Santa Cruz, USA) antibodies were used at a 1:1000 dilution. Bands were visualized by chemiluminescence.

\section{Quantitation}

Experiments were repeated three times. Densitometric analysis of the Western blot film was done with a Bio-Rad Quantity One (Belmont, CA, USA), and the relative densitometry units were calculated relative to $\beta$-actin for each lane.

Statistical analyses were done with the two-tailed $t$-test and $\chi^{2}$ test. $\mathrm{P}<0.05$ was considered to be statistically significant.

\section{RESULTS}

\section{MTT results}

The results of MTT showed that after Gal-3 siRNA treatment, the proliferation of GH3 cells was significantly inhibited in a time-dependent manner (Figure 1). At different time points $(24,48$ and $72 \mathrm{~h}$ ), compared with the control, the proliferation-inhibited effects increased significantly $(\mathrm{P}<0.05)$.

\section{FCM results}

The results of FCM showed that after Gal-3 siRNA treatment, cell apoptosis in GH3 cells increased significantly (Figure 2). Transfection of GH3 cells with pCNC10 Gal-3 antisense plasmid produced the increase in apoptosis, where the proportion of apoptotic cells increased from $5.23 \pm 0.12$ to $21.76 \pm 3.79 \%(\mathrm{P}<0.05)$. Results are reported as the means \pm SE (bars) of three independent experiments.

Expression of Gal-3 measured by Western blot analysis after the treatment of GH3 cells with siRNA 


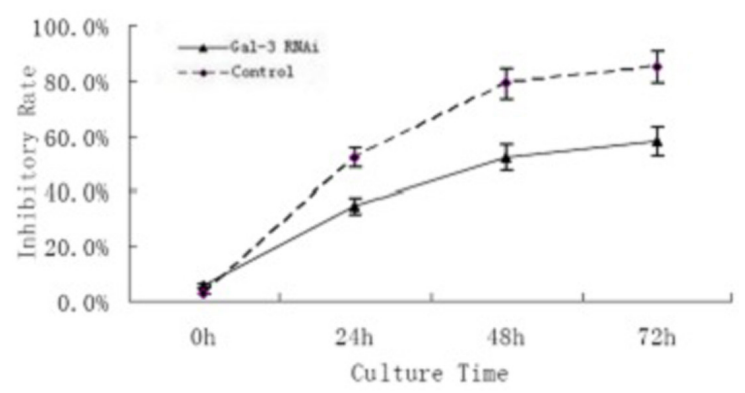

Figure 1. Effects of Gal-3 siRNA treatment on cell proliferation in GH3 cells.
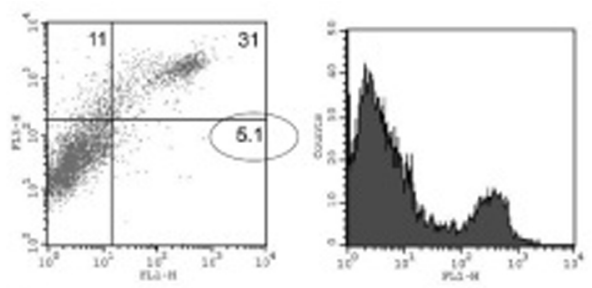

Control
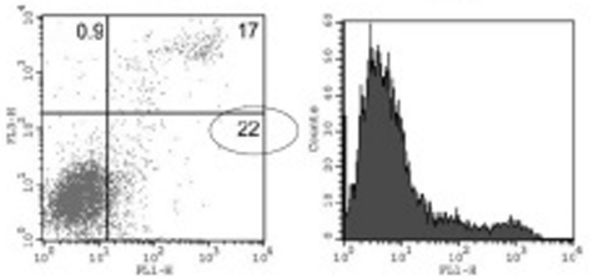

Gal-3 ankai

Figure 2. Effects of Gal-3 siRNA treatment on Cell apoptosis in GH3 cells.

At the time points of 24 and $48 \mathrm{~h}$, the decrease showed a time-dependent manner, but at $72 \mathrm{~h}$, the expression of Gal-3 was upregulated, compared with $48 \mathrm{~h}$, the difference was not significant $(\mathrm{P}>0.05)$. Along with the downregulation of Gal-3, the expression of Bcl-2 decreased significantly $(\mathrm{P}<0.05)$, but that of Bax did not differ $(\mathrm{P}>0.05)$ (Figure 3$)$.

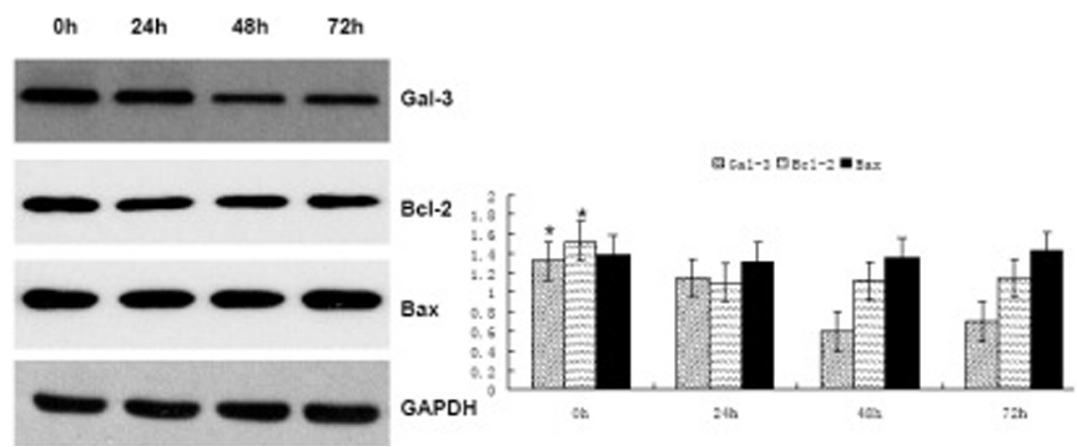

Figure 3. Effects of Gal-3 siRNA treatment on the expressions of Gal-3, Bcl-2, and Bax. 


\section{DISCUSSION}

Galectin-3 is a $31-\mathrm{kDa}$ gene product that serves as an intracellular and extracellular lectin, which is thought to interact with glycoproteins located on the cell surface matrix. Galectin-3 is expressed in various cells and tissues, such as activated macrophages, eosinophils, neutrophils, mast cells, epithelium of the gastrointestinal and respiratory tracts, kidneys and some sensory neurons, and is also involved in tumorigenesis, angiogenesis, and tumor metastasis. Extracellular galectin-3 mediates inflammation, whereas intracellular galectin-3 regulates cell growth and anti-apoptosis, and modulates cell adhesion, thus inducing cell migration (Liu and Rabinovich, 2005; Nangia-Makker et al., 2008; Goetz, 2009).

The group of Raz A was among the first to demonstrate a relationship between galectin expression and the malignant potential of tumors in the central nervous system (Bresalier et al., 1997). Indeed, they showed that the expression level of galectin-3 was significantly associated with astrocytic tumor grade. In contrast, Gordower et al. (1999) found that the level of galectin-3 expression significantly decreased in the majority of astrocytic tumors from low to high grade. However, they also observed that some highly malignant tumor cell clones expressed high amounts of galectin-3. Strik et al. (2001) used immunohistochemistry to identify the cellular origin and extent of galectin-3 positivity in glioma samples. They showed in that study that galectin-3 was expressed in neoplastic astrocytes, macrophages/microglial cells, endothelial cells and some B- and T-lymphocytes. They also pointed out that galectin-3 positivity was considerably influenced by tumor-infiltrating macrophages. The expression level of galectin-3, therefore, seems to be highly dependent on non-tumor cells such as endothelial cells or macrophages/microglial cells. This feature can thus partly explain the conflicting results that have been published on galectin-3 expression in human gliomas (Strik et al., 2001; Deininger et al., 2002).

The regulation of galectin-3 expression by Runx-2 has been recently suggested to contribute to the malignant progression of glial tumors. Runx-2 is a member of the Runx family of transcription factors expressed in a variety of human glioma cells, whose expression pattern in these cells strongly correlates with that of galectin-3, but not with that of other galectins. Knockdown of Runx-2 has been shown to be accompanied by a reduction in both galectin-3 mRNA and protein levels by at least $50 \%$, dependent on the glial tumor cell line tested (Vladimirova et al., 2008).

Zhang et al. (2009) showed for the first time that LGALS3 is upregulated by RUNX1 and RUNX2 in human pituitary tumors and that different RUNX family members bind different DNA sequences in the LGALS3 promoter region. These studies suggest that RUNX1 and RUNX2 upregulate LGALS3 by direct binding to its promoter region and contribute, in part, to pituitary tumor growth regulation. Knockdown of either RUNX1 or RUNX2 by siRNA has resulted in a significant downregulation of galectin-3 expression and decreased cell proliferation in the HP 75 cell line. Immunohistochemistry has shown a close correlation between galectin-3 expression and RUNX1/RUNX2 level in pituitary tumors (Zhang et al., 2009). These results demonstrate a novel binding target for RUNX1 and RUNX2 proteins and suggest that galectin-3 is regulated by RUNX1 and RUNX2 in human pituitary tumor cells by direct binding to the promoter region of LGALS3 and thus may contribute to pituitary tumor progression.

Studies revealed that galectin-3 demonstrates anti-apoptotic effects, which contribute to cell survival in several types of cancer cells. In particular, intracellular galectin-3, which 
contains the NWGR anti-death motif of the Bcl-2 family, inhibits cell apoptosis induced by chemotherapeutic agents such as cisplatin and etoposide in some types of cancer cells (Nakahara et al., 2005). It has also been reported that the nuclear export of phosphorylated galectin-3 regulates its anti-apoptotic activity in response to chemotherapeutic drugs. Indeed anticancer drugs can induce DNA damage, which causes phosphorylated galectin-3 to translocate from the nucleus to the cytoplasm and regulates phosphorylation of Bad, Akt, and extracellular signal-regulated kinase, resulting in stabilization of mitochondrial membrane integrity. The stabilization of the mitochondrial membrane prevents cytochrome $c$ release and subsequent caspase activation, resulting in the suppression of apoptosis and anticancer drug resistance. Finally, it has been suggested that targeting galectin-3 could improve the efficacy of anticancer drug chemotherapy in several types of cancer (Fukumori et al., 2007).

Our study provides the first direct evidence for a role of Gal-3 in pituitary cell proliferation and apoptosis; Gal-3 siRNA reduced Gal-3 expression associated with inhibition of cell proliferation and increased apoptosis in cultured GH3 cells. Transfection of pituitary GH3 cells with pCNC10 Gal-3 antisense also increased apoptosis.

In summary, RNA interference inhibited Gal-3 expression, accompanied by downregulation of Bcl-2 expression, resulted in decreased cell proliferation and increased cell apoptosis in cultured GH3 pituitary cells. These results indicate that Gal-3 may exert its anti-apoptosis effect through $\mathrm{Bcl}-2$, relatively promoting the proliferation of pituitary adenoma cells. It has an important role in pituitary cell proliferation and may serve as a possible therapeutic target to prevent pituitary tumor progression.

\section{ACKNOWLEDGMENTS} (\#30852)

\section{REFERENCES}

Arfaoui-Toumi A, Kria-Ben ML, Ben HM, Khalfallah MT, et al. (2010). Implication of the Galectin-3 in colorectal cancer development (about 325 Tunisian patients). Bull. Cancer 97: E1-E8.

Bresalier RS, Yan PS, Byrd JC, Lotan R, et al. (1997). Expression of the endogenous galactose-binding protein galectin-3 correlates with the malignant potential of tumors in the central nervous system. Cancer 80: 776-787.

Deininger MH, Trautmann K, Meyermann R and Schluesener HJ (2002). Galectin-3 labeling correlates positively in tumor cells and negatively in endothelial cells with malignancy and poor prognosis in oligodendroglioma patients. Anticancer Res. 22: 1585-1592.

Fukumori T, Kanayama HO and Raz A (2007). The role of galectin-3 in cancer drug resistance. Drug Resist. Updat. 10: 101-108.

Goetz JG (2009). Bidirectional control of the inner dynamics of focal adhesions promotes cell migration. Cell Adh. Migr. 3: $185-190$.

Gordower L, Decaestecker C, Kacem Y, Lemmers A, et al. (1999). Galectin-3 and galectin-3-binding site expression in human adult astrocytic tumours and related angiogenesis. Neuropathol. Appl. Neurobiol. 25: 319-330.

Huang CX, Hou YH and Liu YS (2008). Expression of galectin-3 correlates with apoptosis in pituitary adenoma cells. Neurosci. Bull. 24: 34-38.

Jia W, Kidoya H, Yamakawa D, Naito H, et al. (2013). Galectin-3 accelerates M2 macrophage infiltration and angiogenesis in tumors. Am. J. Pathol. 182: 1821-1831.

Lee J, Moon C, Kim J, Jung C, et al. (2009). Immunohistochemical localization of galectin-3 in the granulomatous lesions of paratuberculosis-infected bovine intestine. J. Vet. Sci. 10: 177-180.

Liu FT and Rabinovich GA (2005). Galectins as modulators of tumour progression. Nat. Rev. Cancer 5: 29-41. 
Manivannan P, Siddaraju N, Jatiya L and Verma SK (2012). Role of pro-angiogenic marker galectin-3 in follicular neoplasms of thyroid. Indian J. Biochem. Biophys. 49: 392-394.

Nakahara S, Oka N and Raz A (2005). On the role of galectin-3 in cancer apoptosis. Apoptosis 10: 267-275.

Nangia-Makker P, Balan V and Raz A (2008). Regulation of tumor progression by extracellular galectin-3. Cancer Microenviron. 1: 43-51.

Sakaki M, Fukumori T, Fukawa T, Elsamman E, et al. (2010). Clinical significance of Galectin-3 in clear cell renal cell carcinoma. J. Med. Invest. 57: 152-157.

Strik HM, Deininger MH, Frank B, Schluesener HJ, et al. (2001). Galectin-3: cellular distribution and correlation with WHO-grade in human gliomas. J. Neurooncol. 53: 13-20.

Vladimirova V, Waha A, Luckerath K, Pesheva P, et al. (2008). Runx2 is expressed in human glioma cells and mediates the expression of galectin-3. J. Neurosci. Res. 86: 2450-2461.

Wu SW, Yu L, Zhou L, Cheng ZN, et al. (2013). Expression of Gal-3 and CD82/KAI1 proteins in non-small cell lung cancer and their clinical significance. Zhonghua Zhong Liu Za Zhi 35: 124-128.

Yamaki S, Fujii T, Yajima R, Hirakata T, et al. (2013). Clinicopathological significance of decreased galectin-3 expression and the long-term prognosis in patients with breast cancer. Surg. Today 43: 901-905.

Zhang HY, Jin L, Stilling GA, Ruebel KH, et al. (2009). RUNX1 and RUNX2 upregulate Galectin-3 expression in human pituitary tumors. Endocrine 35: 101-111. 